\title{
Efeito de níveis crescentes de uréia na dieta de vacas em lactação sobre a produção e a composição físico-química do leite ${ }^{1}$
}

\author{
Adriana Augusto Aquino², Bruno Garcia Botaro², Flávio dos Santos Ikeda ${ }^{3}$, Paulo Henrique \\ Mazza Rodrigues ${ }^{4}$, Maria de Fátima Martins ${ }^{4}$, Marcos Veiga dos Santos ${ }^{4}$
}

\footnotetext{
1 Parte de dissertação de Mestrado apresentada à Universidade de São Paulo. Projeto financiado pela FAPESP Proc. 03/01957-5.

2 Pós-graduando da Faculdade de Medicina Veterinária e Zootecnia da Universidade de São Paulo.

${ }^{3}$ Bolsista de Iniciação Científica - FAPESP.

${ }^{4}$ Departamento de Nutrição e Produção Animal da Faculdade de Medicina Veterinária e Zootecnia da Universidade de São Paulo.
}

RESUMO - Avaliou-se o efeito de níveis crescentes de uréia na dieta de vacas em lactação sobre a produção e composição físico-química do leite. Foram utilizadas nove vacas holandesas em lactação, distribuídas em três quadrados latinos 3 x 3, com três tratamentos e três períodos de coleta. O experimento teve duração de 63 dias, divididos em três períodos de 21 dias. Os tratamentos consistiram de uma dieta controle, formulada para suprir 100\% das exigências de PB, proteína degradável no rúmen (PDR) e proteína não-degradável no rúmen (PNDR), composta de farelo de soja como principal fonte protéica e cana-de-açúcar como volumoso, e de duas outras dietas, semelhantes à dieta controle, mas com 0,75 ou 1,5\% de uréia em substituição ao farelo de soja. As dietas foram isoenergéticas (1,53 Mcal/kg de energia líquida de lactação) e isoprotéicas (16\% de PB). Quando os resultados foram analisados por regressão polinomial simples, não houve efeitos das dietas sobre o consumo de MS, as produções de leite e de leite corrigida para 3,5\% de gordura, os teores de proteína e gordura e a contagem de células somáticas do leite. Os níveis de substituição do farelo de soja por uréia não influenciaram o pH, a crioscopia ou a densidade do leite. No entanto, verificou-se efeito linear decrescente dos níveis de uréia na dieta sobre a acidez do leite. Os teores de proteína, gordura, lactose, uréia, extrato seco total e extrato seco desengordurado não foram afetados pelas dietas. Os resultados deste estudo sugerem que o uso de até $1,5 \%$ de uréia na MS da dieta de vacas em lactação não altera a produção, a composição e as características físico-químicas do leite.

Palavras-chave: cana-de-açúcar, consumo de matéria seca, produção e composição do leite, nitrogênio não-protéico, uréia

\section{Effect of increasing dietary urea levels on milk yield and composition of lactating cows}

\begin{abstract}
The objective of this trial was to evaluate the effects of three different dietary levels of urea on milk yield and composition. Nine lactating Holstein cows were randomly assigned to three replicated $3 \times 3$ Latin squares with three periods of 21 days each. Treatments were: A) control diet formulated to meet $100 \%$ of the requirements of crude protein (CP), rumen undegradable protein (RUP) and rumen degradable protein (RDP) according to the NRC (2001) model by feeding soybean meal and sugar cane; B) replacing soybean meal with $0.75 \%$ urea; or C) replacing soybean meal with $1.5 \%$ urea. Diets were formulated to be isonitrogenous (16\% CP) and isocaloric (1.53 Mcal $/ \mathrm{kg}$ of NEl). No significant differences in dry matter intake, milk yield, 3.5\% fat corrected milk, yields of milk protein and milk fat, and somatic cell count were observed among treatments when data were analyzed by simple polynomial regression. Milk cryoscopy, $\mathrm{pH}$ and density were also not affected by increasing the proportion of urea in the diet treatments; however, milk acidity decreased linearly when the levels of urea were increased in the diet. Milk contents of protein, fat, lactose, total solids and non-solids fat and concentration of milk urea all did not differ across diets. Results obtained in this trial indicated that the inclusion of up to $1.5 \%$ of urea (\% of diet DM) in the diet had no effect on milk yield, milk composition, and milk physical-chemical characteristics in lactating cows.
\end{abstract}

Key Words: dry matter intake, milk yield and composition, non protein nitrogen, sugarcane, urea

\section{Introdução}

Além de ser determinante na produção de leite, a nutrição está associada a grande parte dos custos de produção e sanidade do rebanho. Por isso, estratégias que diminuam os custos de alimentação sem interferir negativamente na produção são constantemente pesquisadas (Peres, 2001). A utilização de fontes de nitrogênio não-protéico, entre elas a uréia, é uma das alternativas viáveis para o alcance desses objetivos (Silva et al., 2001; Oliveira et al., 2004). 
Vacas leiteiras alimentadas com dietas com adequada concentração energética podem ser alimentadas com fontes de nitrogênio não-protéico, como a uréia, para suprir suas necessidades de PDR. O uso de dietas contendo até $2 \%$ de uréia na MS parece não alterar a produção de vacas em final de lactação (Carmo et al., 2005). Quando há, simultaneamente, energia disponível da fermentação dos carboidratos e da amônia, a amônia é utilizada para produção de proteína microbiana, que, posteriormente, sofre digestão no abomaso e no intestino delgado, liberando aminoácidos para absorção.

Assim, os microrganismos do rúmen são capazes de sintetizar, a partir de uma fonte de nitrogênio de origem nãoprotéica, os aminoácidos considerados essenciais para a maioria dos mamíferos. No entanto, para que essa síntese seja eficiente, é necessário considerar fatores como relação proteína:energia, quantidade adequada de enxofre para a síntese de aminoácidos sulfurados e relação PDR:PNDR (Forbes \& France, 1993).

No Brasil, o uso de cana-de-açúcar como volumoso para vacas leiteiras é uma boa alternativa para fases de lactação em que a exigência nutricional é mais baixa (Correa et al., 2003). A cana-de-açúcar é um volumoso energético de alta produção por unidade de área e disponibilidade durante todo o ano. A manutenção do valor nutritivo durante todo o seu ciclo pode torná-la uma boa opção para alimentação de bovinos, especialmente durante a seca. No entanto, suas limitações nutricionais devem ser consideradas, visto que os baixos teores de proteína (com aminoácidos sulfurados limitantes), lipídios e minerais, especialmente o fósforo, a baixa digestibilidade da fibra, a ausência de amido e a presença de carboidratos de rápida fermentação resultam em menor consumo de MS (Demarcchi, 2001). No entanto, estudos comprovam que, apesar das limitações nutricionais, o uso racional da cana-de-açúcar pode ser benéfico (Magalhães et al., 2004).

Alguns autores avaliaram o efeito do uso de uréia na dieta de vacas em lactação sobre as características de produção e composição do leite. Imaizumi (2000) verificou que a uréia (1,3\% da MS), associada ao farelo de soja, foi tão eficiente quanto o farelo de soja em suprir aminoácidos à glândula mamária de vacas em final de lactação produzindo entre 12 e $13 \mathrm{~kg}$ de leite/dia. Também ao avaliarem a dieta de vacas em final de lactação, Carmo et al. (2005) não observaram efeito significativo do uso de $2 \%$ de uréia na MS da dieta sobre as características de produção e composição do leite. Por outro lado, Silva et al., (2001) e Oliveira et al. (2001), utilizando níveis crescentes ( $0 ; 0,70 ; 1,4$ e 2,1\%) de uréia na dieta, verificaram diminuição linear no consumo de alimentos e na produção de leite de vacas Girolandas e Holandesas, respectivamente.
O objetivo neste trabalho foi avaliar os efeitos de níveis crescentes de uréia na dieta $(0,0,75$ e 1,5$)$ sobre o consumo de MS, a produção (total e corrigida para 3,5\% de gordura e proteína), as características físico-químicas (pH, crioscopia, acidez e densidade) e a composição (PB, gordura, lactose, uréia, extrato seco total e desengordurado) do leite de vacas leiteiras.

\section{Material e Métodos}

Foram utilizadas nove vacas holandesas adultas (> 2aa lactação), do $2^{\underline{0}}$ ao $7 \underline{0}$ mês de lactação com peso vivo de $560 \mathrm{~kg} \pm 30 \mathrm{~kg}$, hígidas, com contagem de células somáticas no leite (CCS) inferior a 300.000 células/mL e produção de leite de $20 \mathrm{~kg} \pm 5 \mathrm{~kg} /$ dia anteriormente ao período experimental e composição do leite normal (Fonseca \& Santos, 2000). Adotou-se o regime de duas ordenhas diárias, uma realizada no período da manhã (7 h) e a outra no período da tarde (15 h).

Os animais foram alojados no Estábulo Experimental do Departamento de Nutrição e Produção Animal (VNP) da Faculdade de Medicina Veterinária e Zootecnia da Universidade de São Paulo (FMVZ-USP), em Pirassununga-SP, que contava com baias, bebedouros e comedouros individuais, que possibilitaram a avaliação do consumo de alimentos.

O delineamento adotado foi o quadrado latino $3 \times 3$, com três tratamentos, três períodos de 21 dias e com formação de três quadrados (Pimentel Gomes, 1985), respeitando-se um período de adaptação de 17 dias aos animais. A coleta de amostras de leite foi realizada nos quatro últimos dias de cada período.

Os tratamentos foram compostos de três diferentes dietas, fornecidas para cada grupo de três vacas (Tabela 1). A dieta controle foi formulada para suprir $100 \%$ das exigências de PB, PDR e PNDR, de acordo com o NRC (2001), utilizando-se farelo de soja como principal fonte protéica e cana-de-açúcar como volumoso. As outras duas dietas, com 0,75 ou 1,5\% de uréia, foram formuladas para atender 100\% das exigências de PB, segundo o NRC (2001), com manutenção do nível de PB igual ao da dieta controle e canade-açúcar como volumoso.

As dietas foram formuladas para serem isoprotéicas (16\% de PB na MS) e isoenergéticas, com 1,53 Mcal/kg de EL para lactação. As dietas foram fornecidas na forma de mistura completa, duas vezes ao dia (após as ordenhas da manhã e da tarde), em quantidade calculada para ocorrer $5 \%$ de sobras. Foram registrados diariamente a produção de leite das vacas, a ocorrência de sintomas visuais de doenças metabólicas, a incidência de mastite clínica, avaliada pelo teste da caneca de fundo preto, e o consumo de alimentos. 
Tabela 1 - Proporções de ingredientes e composição bromatológica das dietas, com base na MS

Table 1 - Ingredient and chemical composition of the experimental diets, $\%$ of $D M$

\begin{tabular}{|c|c|c|c|}
\hline \multirow[t]{2}{*}{$\begin{array}{l}\text { Ingrediente } \\
\text { Ingredient }\end{array}$} & \multicolumn{3}{|c|}{$\begin{array}{c}\text { Nível de uréia (\%) } \\
\text { Urea level }\end{array}$} \\
\hline & 0 & 0,75 & 1,5 \\
\hline $\begin{array}{l}\text { Cana de açúcar (\%) } \\
\text { Sugarcane }\end{array}$ & 43,35 & 41,42 & 39,50 \\
\hline $\begin{array}{l}\text { Milho grão, moído (\%) } \\
\text { Ground corn grain }\end{array}$ & 28,12 & 34,72 & 41,33 \\
\hline $\begin{array}{l}\text { Farelo de soja (\%) } \\
\text { Soybean meal }\end{array}$ & 25,70 & 20,17 & 14,61 \\
\hline $\begin{array}{l}\text { Uréia 45\% N (\%) } \\
\text { Urea }\end{array}$ & 0 & 0,75 & 1,50 \\
\hline $\begin{array}{l}\text { Fosfato bicálcico (\%) } \\
\text { Dicalcium phosphate }\end{array}$ & 0,39 & 0,50 & 0,62 \\
\hline $\begin{array}{l}\text { Calcário calcítico (\%) } \\
\text { Limestone }\end{array}$ & 0,94 & 0,94 & 0,94 \\
\hline Sal branco (\%) & 0,50 & 0,50 & 0,50 \\
\hline $\begin{array}{l}\text { Salt } \\
\text { Mistura mineral }(\%)^{1} \\
\text { Mineral mixture }\end{array}$ & 1,00 & 1,00 & 1,00 \\
\hline Total & 100 & 100 & 100 \\
\hline $\begin{array}{l}\text { Composição da dieta } \\
\text { Chemical composition }\end{array}$ & & & \\
\hline $\begin{array}{l}\text { MS (\%) } \\
D M(\%)\end{array}$ & 61,82 & 63,85 & 64,03 \\
\hline $\begin{array}{l}\text { PB (\%) } \\
C P(\%)\end{array}$ & 16,17 & 16,33 & 16,21 \\
\hline $\begin{array}{l}\text { PDR }(\% \text { da } \mathrm{PB})^{2} \\
\text { RDP }(\% C P)\end{array}$ & 66,60 & 69,63 & 72,65 \\
\hline $\begin{array}{l}\text { PNDR }(\% \text { da } \mathrm{PB})^{2} \\
\text { RUP }(\% C P)\end{array}$ & 33,40 & 30,37 & 27,35 \\
\hline $\begin{array}{l}\text { FDN (\%) } \\
N D F(\%)\end{array}$ & 31,76 & 30,34 & 29,56 \\
\hline $\begin{array}{l}\text { FDA (\%) } \\
A D F(\%)\end{array}$ & 21,80 & 20,48 & 19,41 \\
\hline EE (\%) & 5,22 & 5,03 & 5,13 \\
\hline $\mathrm{Ca}(\%)$ & 0,72 & 0,72 & 0,80 \\
\hline $\mathrm{P}(\%)$ & 0,46 & 0,44 & 0,45 \\
\hline $\begin{array}{l}\text { EL para lactação }(\mathrm{Mcal} / \mathrm{kg})^{2} \\
\text { NE for lactation }\end{array}$ & 1,53 & 1,53 & 1,53 \\
\hline $\begin{array}{l}\text { Cinzas (\%) } \\
\text { Ash (\%) }\end{array}$ & 4,91 & 4,70 & 4,30 \\
\hline
\end{tabular}

${ }^{1}$ Composição por kg de mistura mineral (mineral mixture composition per $\mathrm{kg}$ ): $\mathrm{Ca}-180 \mathrm{~g} ; \mathrm{P}-90 \mathrm{~g} ; \mathrm{Mg}-20 \mathrm{~g} ; \mathrm{S}-20 \mathrm{~g} ; \mathrm{Na}-100 \mathrm{~g} ; \mathrm{Zn}-3.000 \mathrm{mg}$; $\mathrm{Cu}-1.000 \mathrm{mg} ; \mathrm{Mn}-1.250 \mathrm{mg} ; \mathrm{Fe}-2.000 \mathrm{mg}$; Co - $200 \mathrm{mg}$; I $90 \mathrm{mg}$; Se - $36 \mathrm{mg} ; \mathrm{F}$ (máximo) $(F$, maximum) - $900 \mathrm{mg}$.

2 Estimado segundo NRC (2001) (Estimated according to NRC, 2001).

Durante os quatro últimos dias de cada um dos três períodos experimentais, foram realizadas a pesagem das sobras e a coleta das amostras das dietas e de leite. Os animais foram pesados no início e no final de cada período experimental.

As amostras de cana-de-açúcar e de concentrado, em cada um dos tratamentos, foram acondicionadas em sacos plásticos e armazenadas a $-20^{\circ} \mathrm{C}$ até a realização das análises bromatológicas no Laboratório de Bromatologia do VNPFMVZ-USP. Após a determinação dos teores de MS, realizada de acordo com a Association of Official Analitical Chemists (AOAC, 1990), as amostras foram trituradas em moinho tipo Wiley com peneiras de $1 \mathrm{~mm}$ e analisadas quanto aos teores de PB, EE, cinzas, Ca e P, segundo AOAC (1990), FDN, Van Soest et al. (1991), e FDA, de acordo com Goering \& Van Soest (1970).

As amostras de leite foram coletadas nas duas ordenhas diárias e analisadas, em duplicata, quanto às concentrações de gordura (\%), lactose (\%) e sólidos totais (\%), por absorção infravermelho no equipamento Bentley 2000 (Bentley, 1995), e à contagem de células somáticas (CCS) por citometria fluxométrica no equipamento Somacount 500 (Bentley Instruments Inc. Chasca, MN, USA). A concentração de uréia no leite (mg/dL) foi realizada pelo método colorimétricoenzimático no equipamento Chemspec 150 (Bentley Instruments Inc. Chasca, MN, USA). O pH, a acidez titulável $\left({ }^{\circ} \mathrm{D}\right)$, a densidade $(\mathrm{mg} / \mathrm{dL})$ e a crioscopia $\left({ }^{\circ} \mathrm{H}\right)$ foram determinadas segundo metodologia descrita por Pereira et al. (2001) e o nitrogênio total (NT), pelo método de Kjeldahl descrito pela AOAC (1990). Para conversão do NT em PB, utilizou-se o fator de conversão 6,38 (Barbano \& Clark, 1990).

Todos os resultados foram analisados pelo programa computacional Statistical Analysis System ${ }^{\circledR}$ (SAS, 1985), após verificação da normalidade dos resíduos pelo teste Shapiro-Wilk, pelo procedimento Univariate (análise univariada), e da homogeneidade das variâncias, pelo teste F. Para a contagem de células somáticas, foi realizada a transformação logaritmica $[\log (\mathrm{X}+1)]$. Posteriormente, os resultados originais ou transformados foram submetidos às análises de variância e regressão polinomial simples utilizando-se como fontes de variação o tratamento, o animal dentro de quadrado, de período e de quadrado pelo procedimento GLM (modelo linear geral) a 5\% de significância para todos os testes realizados.

\section{Resultados e Discussão}

As médias do consumo de MS, da produção de leite e de leite corrigida para 3,5\% de gordura, da porcentagem e da produção de gordura, da porcentagem e produção de proteína e do peso vivo, bem como o coeficiente de variação, distribuídos segundo os níveis de uréia na dieta, são apresentados na Tabela 2.

Não foi observado efeito das dietas sobre o consumo de MS, que apresentou variação de 16,3 a 16,74 kg/dia, indicando que a substituição parcial do farelo de soja pela uréia não influenciou o consumo de alimento dos animais. Esses resultados são similares aos obtidos por Carmo et al. (2005), que utilizaram dieta composta de 
silagem de capim-elefante, polpa cítrica peletizada, raspa de mandioca, suplemento vitamínico-mineral e suplemento protéico composto de farelo de soja e $2 \%$ de uréia ou farelo de soja e amiréia e não observaram diminuição no consumo de MS.

Diferentemente dos resultados obtidos neste estudo, Oliveira et al. (2001) e Silva et al. (2001) observaram diminuição linear no consumo de MS ao aumentarem de $0 \%$ para 2,1\% os níveis de uréia na dieta. O período de adaptação de 17 dias, o nível de uréia utilizado e a mistura prévia da uréia ao concentrado podem ter colaborado para que o consumo de MS não fosse influenciado.

Neste estudo, a substituição parcial do farelo de soja por uréia não afetou a produção de leite, com ou sem correção de gordura (Tabela 2), o que pode ser explicado pela manutenção do consumo de MS em todos os grupos avaliados e pelo nível de produção dos animais, cujas exigências de mantença e produção de proteína metabolizável podem ter sido atendidas prioritariamente pela síntese de proteína microbiana. Além disso, para o nível de produção dos animais deste experimento, as exigências de PNDR não foram altas o suficiente para limitar a inclusão de uréia na dieta em até $1,5 \%$ da MS

Resultados semelhantes foram obtidos por Cabrita et al. (2003), que não encontraram diferenças significativas ao utilizarem até $1,0 \%$ de uréia na MS em substituição ao farelo de soja nos concentrados, nos quais a silagem de milho foi o principal volumoso. De modo similar, Dunlap (2000) e Davidson et al. (2003) também não notaram diferenças na produção de leite ao utilizarem dietas com diferentes teores e degradabilidades da proteína dietética. Por outro lado, os estudos de Oliveira et al. (2001), Silva et al. (2001) e Oliveira et al. (2004) comprovaram efeito linear negativo de níveis crescentes de uréia sobre a produção de leite de vacas, o que poderia ser explicado, nesses casos, pela diminuição do CMS.

Tabela 2 - Consumo de MS, produção e composição do leite e peso vivo de vacas alimentadas com dietas contendo uréia Table 2 - DM intake, milk yield and composition, and body weight of cows fed diets with increasing levels of urea

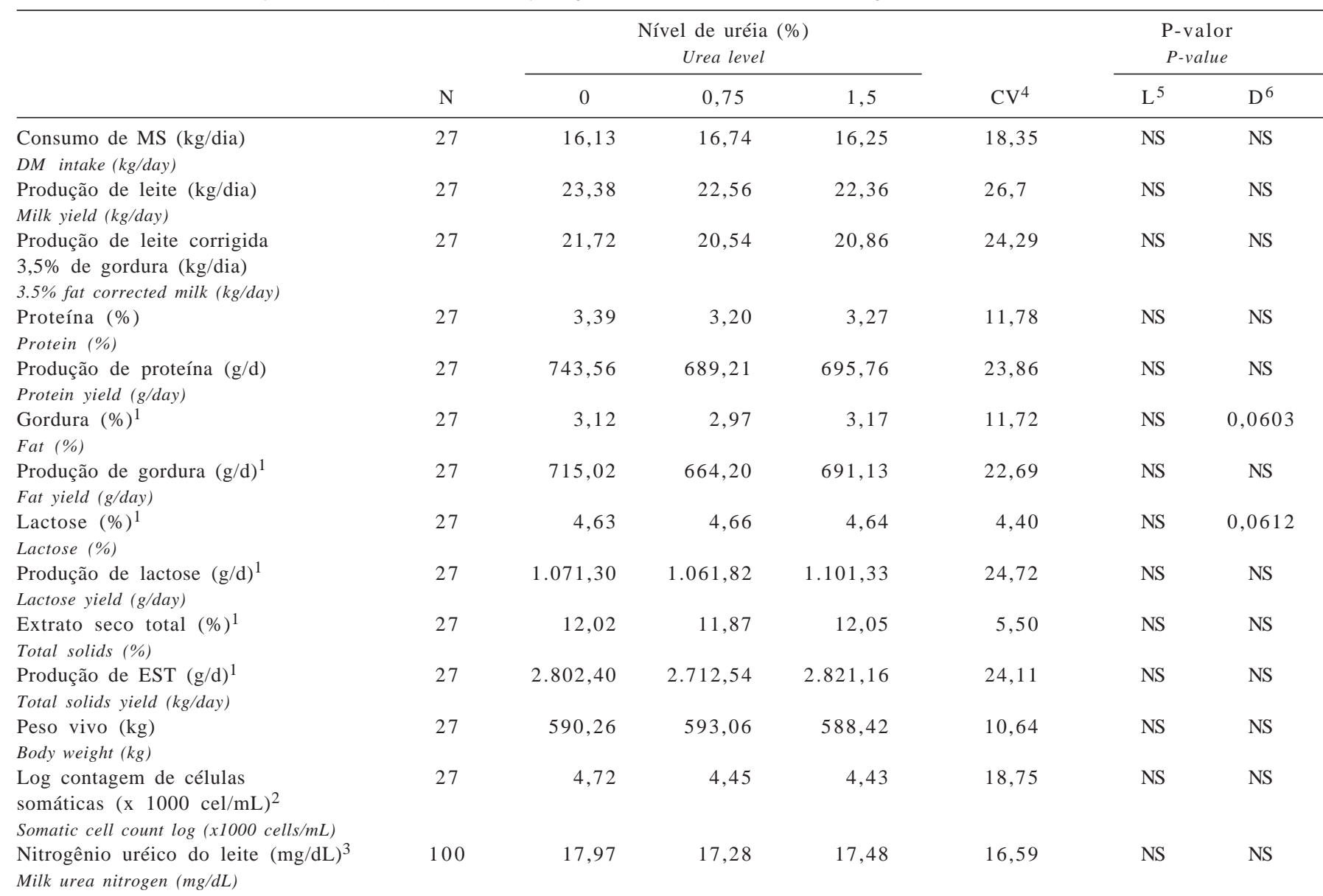

${ }^{1}$ Resultados baseados em análises realizadas pelo método infravermelho (results based on infrared analysis); ${ }^{2}$ Resultados baseados em análises realizadas pelo método de citometria fluxométrica (results based on flusometric citometry analysis); ${ }^{3}$ Resultados baseados em análises realizadas pelo método colorimétrico enzimático (results based on colorimetric enzymatic analysis); ${ }^{4} \mathrm{CV}$ : Coeficiente de variação (coeficient of variation); ${ }^{5}$ Linear (linear): Probabilidade para efeito linea (probability of linear effect); ${ }^{6}$ Desvio (deviation): Probabilidade para efeito de desvio (probability of deviation effect); NS: não-significativo (not significant). 
Santos et al. (1998) forneceram três níveis de PNDR, de diferentes fontes, para vacas em lactação e observaram que a resposta dos animais às diferentes fontes e degradabilidades da proteína depende das características de fermentação da fonte de energia utilizada. Além disso, esses autores afirmaram que a combinação da PNDR com o amido fermentável no rúmen proveniente de sorgo floculado resultou em aumento do consumo de MS e das produções de leite maiores em animais alimentados com uréia. De forma similar, o fornecimento de dietas à base de cana-de-açúcar neste estudo, cujo conteúdo de carboidratos é rapidamente disponível para os microrganismos do rúmen, permitiu o fornecimento de energia necessário para a síntese microbiana de proteína.

O peso vivo não diferiu entre os níveis de uréia utilizados. Resultados semelhantes foram obtidos por Silva et al. (2001), que utilizaram quatro níveis de uréia (0; 0,7; 1,4 e 2,1\%) para vacas leiteiras em início de lactação e demonstraram o atendimento das exigências protéicas e energéticas dos animais. A manutenção do peso vivo dos animais deste estudo pode ter sido ocasionada pelo fato de todos os animais já terem ultrapassado o período de balanço energético negativo e possuírem nível de produção médio (22,7 kg/dia), visto que as exigências nutricionais foram atendidas pela dieta oferecida.

A contagem de células somáticas (CCS) foi utilizada neste estudo para monitorar a ocorrência de mastite subclínica das vacas estudadas, o que poderia influenciar a produção e composição do leite. A CCS foi menor que 200.000 células/mL em todos os tratamentos e não diferiu entre os níveis de uréia na dieta. Esses resultados eram previsíveis, pois a produção de leite foi mantida pelas dietas oferecidas, indicando adequado fornecimento dos nutrientes aos animais.

A composição do leite (proteína, gordura, lactose, extrato seco) também não sofreu influência significativa dos níveis de substituição do farelo de soja pela uréia nas dietas (Tabela 2). O teor de proteína do leite variou de 3,20 a 3,39\% e sua produção foi de 695,76 a 743,56 g/dia. Esses resultados foram semelhantes aos descritos por Christensen et al. (1993), que, ao estudarem o efeito de dois níveis e de duas taxas de degradabilidade de proteína dietética sobre a produção e composição do leite em vacas Holandesas, não encontraram efeito da taxa de degradabilidade nem do nível de proteína dietética sobre a porcentagem e a produção de proteína do leite.

Considerando os resultados deste estudo, a inclusão de até 1,5\% de uréia na MS da dieta de vacas em lactação provavelmente não limitou a capacidade de produção de proteína microbiana no rúmen e atendeu às exigências de proteína metabolizável dos animais. Carmo et al. (2005) também não encontraram diferença significativa da inclusão de uréia sobre o teor ou a produção de PB do leite, enquanto Cameron et al. (1991) observou aumento na produção, mas não na porcentagem de proteína do leite. Neste estudo, a substituição da fonte de proteína verdadeira pelo nitrogênio não-protéico da dieta não alterou a capacidade de produção de proteína no leite (Tabela 2).

O teor e a produção de gordura do leite também não variaram entre os tratamentos. Os níveis médios de gordura do leite foram inferiores ao esperado e variaram de 2,97 a $3,17 \%$, o que pode estar relacionado ao consumo médio de concentrado (9,13; 9,80 e 9,83 kg MS/dia nas dietas com 0; 0,75 e 1,5\% de uréia, respectivamente), visto que a canade-açúcar foi usada como único volumoso. O consumo médio de MS em relação ao peso vivo foi de 2,88; 2,98 e 2,9 kg MS/dia para as dietas com 0; 0,75 e 1,5\% de uréia, respectivamente, o que pode ser considerado adequado para vacas em lactação. A produção de gordura apresentou variação de 664,2 a 715,02 g/dia. Carmo et al. (2005) verificaram aumento no teor e na produção de gordura no leite dos animais alimentados com dieta contendo uréia em substituição parcial ao farelo de soja, o que difere dos resultados obtidos neste estudo. No entanto, Baker et al. (1995) não encontraram diferenças na porcentagem de gordura do leite atribuídas à variação na quantidade e na relação PDR:PNDR.

O teor de lactose no leite não diferiu entre as três dietas, o que era previsível, pois a lactose é o componente do leite que menos sofre alteração em decorrência da dieta, tendo em vista seu importante papel osmótico no leite (Fonseca \& Santos, 2000). Assim, mudanças na nutrição das vacas leiteiras normalmente não modificam a concentração e produção de lactose, o que, possivelmente, está relacionado a fatores ambientais. A faixa de variação do teor de lactose (4,63 a 4,66\%) está nos limites esperados para vacas leiteiras.

Considerando a similaridade dos teores de proteína, gordura e lactose do leite entre as dietas testadas, era previsível a ausência de efeitos das dietas sobre o teor de extrato seco do leite. Resultados similares foram descritos por Keery \& Amos (1993), porém, diferem dos relatados por Carmo et al. (2005), que descreveram maior teor de sólidos totais no leite de animais alimentados com dietas contendo $2 \%$ de uréia, embora a produção não tenha sido diferente.

Neste estudo, é importante a mensuração da concentração de N-uréico no leite, pois constitui uma importante medida indireta para determinação da eficiência de utilização do nitrogênio pelo ruminante e por estar fortemente 
Tabela 3 - Características físico-químicas do leite cru de vacas leiteiras alimentadas com dietas contendo uréia Table 3 - Physical-chemical characteristics of milk of cows fed diets with increasing levels of urea

\begin{tabular}{|c|c|c|c|c|c|c|c|}
\hline \multirow[t]{2}{*}{$\begin{array}{l}\text { Característica } \\
\text { Item }\end{array}$} & \multirow[b]{2}{*}{$\mathrm{N}$} & \multicolumn{3}{|c|}{$\begin{array}{c}\text { Nível de uréia (\%) } \\
\text { Urea level }\end{array}$} & \multirow[b]{2}{*}{$\mathrm{CV}^{1}$} & \multicolumn{2}{|c|}{$\begin{array}{l}\text { P-valor } \\
P \text {-value }\end{array}$} \\
\hline & & 0 & 0,75 & 1,5 & & $\mathrm{~L}^{2}$ & $\mathrm{D}^{3}$ \\
\hline Acidez $\left({ }^{\circ} \mathrm{D}\right)$ & 27 & 17,78 & 17,33 & 16,75 & 7,97 & 0,0171 & NS \\
\hline \multicolumn{8}{|l|}{ Acidity } \\
\hline Crioscopia $\left({ }^{\circ} \mathrm{H}\right)$ & 27 & $-0,543$ & $-0,545$ & $-0,54$ & 1,67 & NS & NS \\
\hline Densidity $(\mathrm{mg} / \mathrm{mL})$ & & & & & & & \\
\hline
\end{tabular}

${ }^{1} \mathrm{CV}$ : Coeficiente de variação (coefficient of variation); ${ }^{2}$ Linear (linear): Probabilidade para efeito linear (probability of linear effect); ${ }^{3}$ Desvio (deviation): Probabilidade para efeito de desvio (probability of deviation effect); NS: não-significativo (not significant).

correlacionado à concentração de N-uréico no plasma (DePeters \& Fergunson, 1992). Neste estudo, os níveis de uréia da dieta não influenciaram a concentração de N-uréico no leite, sendo obtidas médias de 17,97; 17,28 e $16,59 \mathrm{mg} / \mathrm{dL}$ com as dietas com 0; 0,75 e 1,5\% de uréia, respectivamente. Esses valores encontram-se na variação normal de $12-18 \mathrm{mg} / \mathrm{dL}$ preconizada para vacas em lactação (Torrent, 2000) e indicam que, até o nível de inclusão de 1,5\% de uréia na MS das dietas, não houve excreção de excesso de uréia no leite.

As médias referentes às características físico-químicas do leite ( $\mathrm{pH}$, acidez, crioscopia e densidade), o coeficiente de variação e as probabilidades de efeito linear (L) e desvio (D) são apresentados na Tabela 3.

A análise das características físico-químicas é uma forma de avaliar a adequação do leite ao processamento pela indústria de laticínios, além de ser um indicativo de qualidade e de adequação do manejo nutricional dos rebanhos leiteiros. Fatores como pH, densidade, acidez e índice crioscópico são influenciados pelas concentrações de água, proteína e gordura no leite e estas concentrações são marcadamente influenciadas pela nutrição. Neste estudo, não houve diferenças para $\mathrm{pH}$, densidade e índice crioscópico. No entanto, a acidez sofreu efeito linear decrescente dos níveis de uréia da dieta ( $\mathrm{P}=0,017)$, cujas médias foram menores $\left(16,75^{\circ} \mathrm{D}\right)$ nos animais alimentados com a dieta contendo $1,5 \%$ de uréia e maiores para aqueles da dieta com $0 \%$ de uréia. Não foram encontrados na literatura estudos sobre os efeitos da inclusão de uréia na dieta sobre a acidez do leite. De qualquer modo, essa redução poderia ser explicada caso houvesse aumento das concentrações de amônia no leite (a molécula de amônia possui caráter básico), no entanto, essa análise não foi realizada neste estudo.

\section{Conclusões}

A uréia, adicionada ao concentrado em níveis de até 1,5\% na MS da dieta e fornecida na dieta completa, não alterou o consumo de MS de vacas leiteiras. A densidade, a crioscopia e o pH do leite não foram influenciados pela inclusão de até $1,5 \%$ de uréia na MS da dieta de vacas em meio de lactação, no entanto, a acidez apresentou redução linear conforme aumentou o nível de uréia na dieta. A composição do leite não foi afetada pela substituição do farelo de soja pela uréia. Nas condições deste experimento, a utilização de até $1,5 \%$ de uréia na MS da dieta de vacas em meio de lactação não altera o desempenho produtivo e as características físico-químicas e de composição do leite.

\section{Literatura Citada}

ASSOCIATION OF OFFICIAL ANALYTICAL CHEMISTS - AOAC. Official methods of analysis. 11.ed. Arlington: 1990. 1050p. BAKER, L.D.; FERGUNSON, J.D.; CHALUPA, W. Responses in urea and true protein feeding schemes for protein of milk to different dairy cows. Journal of Dairy Science, v.78, n.11, p.2424-2434, 1995.

BARBANO, D.M.; CLARK, J.L. Kjeldahl method for determination of total nitrogen content of milk: collaborative study. Journal AOAC International, v.73, p.849-859, 1990.

BENTLEY INSTRUMENTS. Bentley 2000: operator's manual. Chasca, 1995.

BENTLEY INSTRUMENTS. Somacount 500: operator's manual. Chasca, 1995.

CABRITA, A.R.J.; FONSECA, A.J.M.; DEWHURST, R.J. et al. Nitrogen supplementation of corn silages. 1. Effects on feed intake and milk production of dairy cows. Journal of Dairy Science, v.86, n.12, p.4008-4019, 2003.

CAMERON, M.R.; KLUSMEYER, T.H.; LYNCH, G.L. et al. Effects of urea and starch on rumen fermentation, nutrient passage to the duodenum, and performance of cows. Journal of Dairy Science, v.74, n.4, p.1321-1336, 1991.

CARMO, C.A.; SANTOS, F.A.P.; IMAIZUMI, H. et al. Substituição do farelo de soja por uréia ou amiréia para vacas em final de lactação. Acta Scientiarum, v.27, n.2, p.277-286, 2005. 
CHRISTENSEN, R.A.; LYNCH, G.L.; CLARCK, J.H. et al. Influence of amount and degradability of protein on production of milk and milk components by lactating Holstein cows. Journal of Dairy Science, v.76, n.11, p.3490-3496, 1993.

CORREA, C.E.S.; PEREIRA, M.N.; OLIVEIRA, S.G. et al. Performance of Holstein cows fed sugarcane or corn silages of different grain textures. Scientia Agricola, v.60, n.4, p.621629, 2003.

DAVIDSON, S.; HOPKINS, B.A.; DIAZ, D.E. et al. Effects of amounts and degradability of dietary protein on lactation, nitrogen utilization, and excretion in early lactation Holstein cows. Journal of Dairy Science, v.86, n.5, p.1681-1689, 2003

DEMARCCHI, J. O uso da cana-de-açúcar como recurso forrageiro. In: SIMPÓSIO DE MANEJO DE PASTAGENS, 18., 2001, Piracicaba. Anais... Piracicaba: Escola Superior de Agricultura Luiz de Queiroz, 2001. p.84.

DEPETERS, E.J; FERGUNSON, J.D. Nonprotein nitrogen and protein distribution in the milk of cows. Journal of Dairy Science, v.75, p.3192-3209, 1992

DUNLAP, T.F.; KOHN, R.A.; DOUGLASS, L.W. et al. Diets deficient in rumen undegraded protein did not depress milk production. Journal of Dairy Science, v.83, n.8, p.18061812, 2000.

FONSECA, L.F.L.; SANTOS, M.V. Qualidade do leite e controle de mastite. São Paulo: Lemos Editorial, 2000. 176p.

FORBES, J.M; FRANCE, J. Quantitative aspects of ruminant digestion and metabolism. Oxon: Cab International, 1993. $515 p$.

GOERING, H.K.; Van SOEST, P.J. Forage fiber analysis (apparatus, reagents, procedures, and some applications). Washington: United States Department of Agriculture Agricultural Research Service, 1970. (Agricultural Handbook, 379).

IMAIZUMi, H. Avaliação de diferentes fontes e teores de proteína degradável no rúmen sobre o desempenho e parâmetros ruminais e sanguíneos de vacas Holandesas em final de lactação. Piracicaba: Escola Superior de Agricultura Luiz de Queiroz, 2000. 69p. Dissertação (Mestrado) - Escola Superior de Agricultura Luiz de Queiroz, 2000.

KERRY, C.M.; AMOS, H.E.; FROETSCHEL, M.A. Effects of supplemental protein source on intraruminal fermentation, protein degradation and amino acid absorption. Journal of Dairy Science, v.76, n.2, p.514-524, 1993.

MAGALHÃES, A.L.R.; CAMPOS, J.M.S.; VALADARES FILHO, S.C. et al. Cana-de-açúcar em substituição à silagem de milho em dietas para vacas em lactação: desempenho e viabilidade econômica. Revista Brasileira de Zootecnia, v.33, n.5, p.1292-1302, 2004.
NATIONAL RESEARCH COUNCIL - NRC. Nutrient requirements of dairy cattle. Washington, D.C.: National Academy of Science, National Academy Press, 2001. 381p.

OLIVEIRA, A.S.; VALADARES, R.F.D.; VALADARES FILHO, S.C. et al. Consumo, digestibilidade aparente, produção e composição do leite de vacas alimentadas com quatro níveis de compostos nitrogenados não-protéicos. Revista Brasileira de Zootecnia, v.30, n.4, p.1358-1366, 2001.

OLIVEIRA, M.M.N.F.; TORRES, C.A.A.; VALADARES FILHO, S.C. et al. Urea for postpartum dairy cows: productive and reproductive performance. Revista Brasileira de Zootecnia, v.33, n.6, p.2266-2273, 2004.

PEREIRA, D.B.C.; SILVA, P.H.F.; COSTA JR., L.C.G. et al. Físicoquímica do leite e derivados - métodos analíticos. Juiz de Fora: Epamig, 2001. 234p.

PERES, J.R. O leite como ferramenta do monitoramento nutricional. In: GONZÁLEZ, F.D; DURR, J.W.; FONTANELI, R.S. (Eds.) Uso do leite para monitorar a nutrição e o metabolismo de vacas leiteiras. Porto Alegre: Universidade Federal do Rio Grande do Sul, 2001. p.30-45.

PIMENTEL GOMES, F. Curso de estatística experimental. Piracicaba: Escola Superior de Agricultura Luiz de Queiroz, 1985. 467p.

STATISTICAL ANALYSES SYSTEM - SAS. SAS user's guide: statistics. 5.ed. Cary: 1985. (CD-ROM).

SANTOS, F.A.P; HUBER, J.T; THEURER, C.B. et al. Milk yield and composition of lactating cows fed steam-flaked sorghum and graded concentrations of ruminally degradable protein. Journal of Dairy Science, v.81, p.215-220, 1998.

SILVA, R.M.N.; VALADARES, R.F.D.; VALADARES FILHO, S.C. et al. Uréia para vacas em lactação. 1. Consumo, digestibilidade, produção e composição do leite. Revista Brasileira de Zootecnia, v.30, n.5, p.1639-1649, 2001.

TORRENT, J. Nitrogênio uréico no leite e qualidade do leite. In: SIMPÓSIO INTERNACIONAL SOBRE QUALIDADE DO LEITE, 2., 2000, Curitiba. Anais... Curitiba: Associação Paranaense de Criadores de Bovinos da Raça Holandesa, 2000. p. 98.

Van SOEST, P.J.; ROBERTSON, J.B.; LEWIS, B.A. Methods for fiber, neutral detergent fiber, and nonstarch polysaccharides in relation to animal nutrition. Journal of Dairy Science, v.74, p.3583-3597, 1991. 